\title{
O IMIGRANTE E O RESPEITO ÀS SUAS LIBERDADES INSTRUMENTAIS NO BRASIL
}

Tânia Regina Silva Garcez Mestra em Direito - PPGD-UFMS taniarsgarcez@gmail.com

Ana Paula Martins Amaral Docente do Programa de Pós Graduação -Mestrado em Direito. PPGD-UFMS anapaulamartinsa@yahoo.com.br

\begin{abstract}
RESUMO
O objetivo do presente artigo foi trazer a visão sobre as liberdades instrumentais do imigrante no Brasil. Os objetivos específicos foram: conhecer a migração e a cidadania frente ao direito do desenvolvimento e o respeito à sua liberdade instrumental. A pesquisa usou o método dedutivo com pesquisa exploratória, bibliográfica, documental e descritiva, visando destacar o direito ao desenvolvimento do imigrante no Brasil. Em razão do princípio de respeito à dignidade da pessoa humana, dos instrumentos internacionais de proteção de Direitos Humanos e da vasta normatização brasileira voltada ao imigrante apontada nesse trabalho, verificou-se que toda pessoa deve ter seus direitos respeitados pelo simples fato de pertencer à humanidade, independentemente de qualquer outra circunstância.
\end{abstract}

Palavras-Chave: Cidadania; Migração Internacional; Liberdade. 


\section{ABSTRACT}

\section{THE IMMIGRANT AND RESPECT FOR THEIR INSTRUMENTAL FREEDOMS IN BRAZIL}

The aim of this article was to bring the view on the instrumental freedoms of immigrants in Brazil. The specific objectives were to know migration and citizenship in the face of the right of development and respect for their instrumental freedom. The research used the deductive method with exploratory, bibliographic, documentary and descriptive research, aiming to highlight the right to immigrant development in Brazil. Due to the principle of respect for the dignity of the human person, the international instruments of protection of human rights and the vast Brazilian norms aimed at the immigrant pointed out in this work, it was found that every person should have his rights respected by the mere fact of belonging to humanity, regardless of any other circumstance.

Keywords: Citizenship; International Migration; freedom. 


\section{INTRODUÇÃO}

Com a globalização, os movimentos migratórios ocorreram e ainda ocorrem maciçamente em escala mundial e, apesar de, ao longo de toda sua história, o Brasil ter recebido fluxos migratórios das mais diversas partes do mundo, atualmente, oriundos, na maioria, de seus vizinhos da América do Sul, apenas recentemente, em 2017, com a aprovação da Lei de Migração (Lei no 13.445/2017), os direitos humanos, que são princípios fundamentais constitucionais brasileiros desde 1988, quando foi promulgada a Constituição Federal de 1988, foram adotados como marco legal sobre a política migratória brasileira.

A demora em se reformular a legislação migratória, apesar das iniciativas nesse sentido, decorreu, segundo Silva (2015), de uma falta de vontade política e de consenso entre os diferentes atores políticos, pelo menos, desde o início da década de 1990.

A Lei no 13.445/2017, nova Lei de Migração, pode ser considerada um avanço no campo dos direitos humanos, cujo texto mostra o interesse da reversão de pontos arenosos, como a personalidade militarista, ainda identificável no Estatuto do Estrangeiro, Lei no 6.815/1980, reflete, também, um movimento de atualização e de aproximação às pautas de direitos e questões humanitárias mundialmente consolidadas.

A nova Lei no 13.445/2017 sinaliza seus interesses a partir de uma própria e interna renovação conceitual, não mais se refere ao termo estrangeiro, mas sim, migrante. Inova no ordenamento jurídico, ao trazer os direitos humanos como tema central da política migratória que, até então, era permeada pela ideologia de segurança nacional. Busca a proteção para o migrante e, para isso, tem-se a necessidade de constante diálogo com as Leis já vigentes no país e com os tratados e documentos internacionais, os quais o Brasil ratificou.

Essa norma, que teve vacatio legis de 180 dias, entrou em vigor em 21 de novembro de 2017 e, ao substituir a Lei no 6.815/1980, Estatuto do Estrangeiro, visou interligar a política migratória brasileira, de acordo com a Constituição de 1988. Introduz em seu Art. 3ํa a base principiológica dessa nova política, que é regida pela "universalidade, indivisibilidade e interdependência dos direitos humanos" (BRASIL, 2017, online). Desse modo, ao situar topograficamente os princípios de direitos humanos, destaca-os como parâmetros hermenêuticos da Lei e alinha, axiologicamente, a política migratória ao regime jurídicoconstitucional de prevalência dos direitos humanos. Nessa perspectiva, se faz necessário 
verificar, primeiramente, a compatibilidade da Lei de Migração e das demais normas brasileiras, numa concepção ampla de cidadania, se está a promover ou não o direito ao desenvolvimento do imigrante no país.

A questão do presente artigo resumiu-se em saber qual a visão sobre as liberdades instrumentais do imigrante no Brasil?

O objetivo do presente artigo foi trazer a visão sobre as liberdades instrumentais do imigrante no Brasil. Os objetivos específicos foram: conhecer a cidadania do migrante e seu direito ao desenvolvimento e apresentar o desenvolvimento do imigrante no ordenamento jurídico brasileiro, as liberdades políticas e as facilidades econômicas ao imigrante no Brasil.

A pesquisa usou o método dedutivo com pesquisa exploratória, bibliográfica, documental e descritiva.

\section{MIGRAÇÃO E CIDADANIA DIANTE DO DIREITO AO DESENVOLVIMENTO}

O atual conceito de cidadania tem significado dinâmico e deve ser considerado em suas dimensões mais amplas e conectado com a permanente evolução dos direitos humanos. Isso acontece não somente por causa das regras de nacionalidade que definem quem tem ou não cidadania, mas por causa dos diferentes direitos que marcam o cidadão em cada Estado e perante a comunidade internacional. Assim, cidadania hoje engloba direitos civis, políticos, econômicos, sociais, difusos e está interligada aos valores como liberdade, justiça, igualdade e solidariedade.

O processo de globalização e a constante imigração propiciaram profundas transformações nas relações entre indivíduos e Estado, especialmente, no campo do direito internacional dos direitos humanos, no qual as necessidades humanas passaram a ser manifestadas regional e internacionalmente, visando concretizar o princípio da dignidade humana e investigar o elo entre cidadania e direitos humanos (MEZZAROBA; SILVEIRA, 2018).

As notáveis transformações no cenário mundial, desencadeadas a partir de 1989, pelo fim da guerra fria e a irrupção de numerosos conflitos internos, caracterizaram os anos noventa como um momento na história contemporânea marcado por uma profunda reflexão, em escala universal, sobre as próprias bases da sociedade internacional e a formação gradual da agenda internacional do século XXI. Seu denominador comum tem sido a atenção especial 
às condições de vida da população, em particular dos que integram os grupos vulneráveis, que têm necessidade especial de proteção. Com efeito, os grandes desafios desse século, -a proteção do ser humano e do meio ambiente, a superação das disparidades alarmantes entre os países e dentro deles, assim como da exclusão social, a erradicação da pobreza crônica e o fomento ao desenvolvimento humano e o desarmamento-, têm incitado à revitalização dos próprios fundamentos e princípios do Direito Internacional contemporâneo, tendendo a fazer abstração de soluções jurisdicionais e espaciais (territoriais) clássicas, deslocando a ênfase para a noção de solidariedade (TRINDADE, 2006).

As poucas pesquisas que já foram realizadas sobre a Nova Lei de Migração, nesse sentido, conforme. Dupas (2018), Vedovato (2018) e, Amaral e Costa (2017), indicam que ao facilitar a inclusão dos imigrantes na sociedade brasileira e tratar a migração como tema de direitos humanos e não mais de segurança nacional, o Brasil posiciona-se na contramão de muitos países na atualidade.

Numerosos países continuam a fazer vista grossa para a migração ilegal ou legal, aceitando trabalhadores estrangeiros temporários porque almejam se beneficiar de sua energia, talento e seu trabalho barato, e acabam se recusando a legalizar o status dessas pessoas, alegando que não querem imigração, gerando, assim, sociedades hierárquicas, onde uma classe de "cidadãos" explora uma subclasse de "estrangeiros impotentes", como acontece hoje no Qatar e em diversos outros Estados do Golfo (HARARI, 2018).

Vedovato (2018, p. 19), explica que, a necessidade do Brasil e dos demais países do globo, em pensar a migração como tema sobressalente de direitos humanos é urgente e improrrogável já que:

A liberdade total do Estado para definir quem entra no seu território desapareceu com o surgimento dos tratados de direitos humanos. Ou seja, os Estados estão inseridos em um contexto de tratados internacionais, aos quais necessariamente devem reportar-se e que chamamos de sistema internacional de proteção aos direitos humanos.

O atual significado de cidadania é dinâmico, devendo ser pensada em dimensões mais amplas, estando imbricada com a constante evolução dos direitos humanos. Ambos, cidadania e direitos humanos, configuram um conceito histórico, o que faz com que seus sentidos se 
modifiquem no tempo e no espaço, acompanhando o progresso da humanidade (CAMPELLO; SILVEIRA, 2010).

Santos (2006) propõe a combinação de formas individuais com formas coletivas de cidadania, apontando para ampliação do conceito de cidadania tanto quanto para além da ideia de reciprocidade e equivalência entre direitos e deveres. Nesse sentido, pode-se compreender que a condição jurídica do estrangeiro está, eminentemente, fadada a sofrer uma reestruturação, vez que carece de controles quanto à constitucionalidade das normas limitadoras dos direitos humanos, tidos como fundamentais.

O Direito Trabalhista, os Estatutos regulatórios e o próprio Direito Civil elevam os nacionais a nível garantidor superior aos dos estrangeiros, mantendo certa proteção aos primeiros, de toda sorte ilusória, em face de uma visão transcendental, principalmente histórica, tanto ao se considerar o berço da colonização, quanto à transitoriedade que o instituto da nacionalidade contempla (SALERNO; BERTACO, 2007).

Quanto à proteção aos migrantes ressalta-se que, não são apenas a vida e a saúde, bens passíveis de serem protegidos, mas tudo aquilo que seja digno de proteção, a partir do ponto de vista dos direitos fundamentais como, por exemplo, a dignidade, a liberdade, a família, a propriedade, o seu desenvolvimento como pessoa humana. São diversas as formas de viabilizar a proteção, como a proteção por meio de normas de direito penal, de responsabilidade civil, de direito processual, por meio de atos administrativos e ou por meios de ações fáticas.

\subsection{O DESENVOLVIMENTO DO IMIGRANTE NO ORDENAMENTO JURÍDICO BRASILEIRO}

O desenvolvimento do ser humano pressupõe liberdade. A partir do presente subtítulo verifica-se a adequação das normas brasileiras à garantia do desenvolvimento do imigrante no país. Como Baeninger (2013) aponta, as migrações internacionais vêm adquirindo papel cada vez mais importante no cotidiano social, na mobilidade da força de trabalho, no mercado de trabalho, nas sociedades de chegada e partida, no fluxo financeiro, na vida dos imigrantes e o desenvolvimento do país que escolhem como destino. É parte integrante do desenvolvimento, reflete e é refletido na divisão do trabalho. 
A fim de responder se as normas do direito brasileiro são adequadas à promoverem o desenvolvimento do imigrante no Brasil e se estão efetivamente cumprindo sua função de resguardar esse desenvolvimento por meio de liberdades instrumentais, como apresentadas por Sen (2010), propôs-se fazer um estudo mais legalista que doutrinário, levando em conta as cinco liberdades instrumentais diante do ordenamento jurídico brasileiro, quais sejam, liberdades políticas; facilidades econômicas; oportunidades sociais; garantias de transparência e segurança protetora.

As liberdades instrumentais são meios importantes que se fortalecem mutuamente $e$ auxiliam, de modo geral, a implementação de políticas públicas e de leis que se fazem decisivas para o exercício da liberdade global, além do que, o papel instrumental da liberdade se relaciona com os diversos tipos de direitos, oportunidades e habilitações que colaboram para o aumento da liberdade humana geral, e assim, são essenciais para as capabilidades das pessoas e do desenvolvimento social. Elas possuem valor próprio, mas é por meio da intensidade, com que acontecem a interação e a complementaridade, que o desenvolvimento se fortalece. A inter-relação entre as liberdades instrumentais é necessária, percebida e sedimentada nos encadeamentos empíricos, que se processam no interior das relações sociais, reforçando-se umas às outras (ZAMBAM, 2009).

Zambam (2009) faz um minucioso estudo sobre as liberdades instrumentais de Sen (2010), trazendo sua importância e características específicas: 1 As liberdades políticas dizem respeito à participação do indivíduo nas ações que se referem ao governo e suas organizações, interesses e meios que permitem ao povo como um todo, exercer a cidadania, a exemplo do direito de participar das eleições, liberdade para escolher, liberdade de imprensa, a seleção e a inspeção dos governantes, entre outros.

2. As facilidades econômicas tratam dos recursos econômicos necessários, sejam eles naturais ou não, inclusive incluem as oportunidades imprescindíveis e satisfatórias para comercializar, para trabalhar, distribuição de renda e riqueza, acesso ao crédito, dentre outros (ZAMBAM, 2009).

3. Oportunidades sociais são as chances que os governos propiciam para uma melhor qualidade de vida da população, a exemplo da saúde, educação, dentre outras, como erradicar o analfabetismo, notadamente, entre mulheres que vivem em sociedades nas quais são 
discriminadas, e os planos de saúde de abrangência coletiva são extraordinários meios para desempenho das liberdades (ZAMBAM, 2009).

4. Segurança protetora diz respeito aos instrumentos organizacionais, que permitem a proteção da população em situação de extrema pobreza, garantindo que nenhuma pessoa em situação de risco fique sem condições de obter seguridade social, em casos de desastres ambientais, épocas de seca, dentre outros; do mesmo modo, prevenir situações especiais, a exemplo, desemprego, vacinação em massa ou aplicação recursos para moradia, saneamento básico ou obras de infraestrutura (ZAMBAM, 2009).

5. As garantias de transparência dizem respeito ao direito de se ter relações límpidas, claras, tanto em relação aos indivíduos como, também, desses com a coletividade, incluindo organismos controladores organizacionais. A transparência assegura que tudo que é realizado pode ser conhecido por todos, livremente, sem que nada fique escondido, ou seja, confidencial e é protegida juridicamente, tendo função de eliminar a corrupção, a falta de responsabilidade financeira e atos ilícitos (ZAMBAM, 2009).

\subsubsection{O BRASIL E AS LIBERDADES POLÍTICAS DO IMIGRANTE}

A Constituição Federal de 1988 não positivou expressamente os objetivos da política migratória no Brasil, entretanto, desde o seu preâmbulo, o constituinte originário expressou os valores de "uma sociedade fraterna pluralista e sem preconceitos" e dispôs como objetivo fundamental República Federativa do Brasil: “Art. 3 [...] IV - promover o bem de todos, sem preconceitos de origem, raça, sexo, cor, idade e quaisquer outras formas de discriminação" (BRASIL, 1988, online, grifo nosso).

Posteriormente o texto constitucional retrata os princípios que vigoram nas relações internacionais do Brasil: "Art.4으...] II - prevalência dos direitos humanos" e a busca pela "[...] integração econômica, política, social e cultural dos povos da América Latina, visando à formação de uma comunidade latino-americana de nações" (BRASIL, 1988, online).

Além do que, o constituinte, implicitamente, assentiu a importância da participação dos braços migrantes na construção do país, ao estabelecer, no Art. $242, \S 1$, que: “[...] ensino da História do Brasil levará em conta as contribuições das diferentes culturas e etnias para a formação do povo brasileiro" (BRASIL, 1988, online). 
Seria, então, possível deduzir que uma política migratória restritiva, não acolhedora e xenófoba não poderia ser compatível com o ordenamento constitucional do país, porém, a Carta não rompe em definitivo com a política migratória de Estado Nacional Soberano e não Cooperativo (HÄRBELE, 2007), já que limita o conceito de cidadania ao direito de votar e ser votado e institui expressamente o conceito de soberania popular somente aos seus nacionais natos ou naturalizados. Como demonstra o Artigo 14, da Constituição Federal de 1988, online, in verbis:

[...] a soberania popular será exercida pelo sufrágio universal e pelo voto direto e secreto, com valor igual para todos, e, nos termos da lei, mediante: [...] $\S 100$ alistamento eleitoral e o voto são: I - obrigatórios para os maiores de dezoito anos; II - facultativos para: a) os analfabetos; b) os maiores de setenta anos; c) os maiores de dezesseis e menores de dezoito anos [...] § 20 Não podem alistar-se como eleitores os estrangeiros e, durante o período do serviço militar obrigatório, os conscritos. § 3오ão condições de elegibilidade, na forma da lei: I - a nacionalidade brasileira (grifo nosso).

Reis (2008, p. 4), enfatiza que, ainda que a pessoa ou candidato se torne inelegível, o mais importante, em termos de soberania, é o direito ao voto, visto que seja esse ato, um ato fundamental para a cidadania. Veja-se,

De fato, embora o exercício da soberania implique tanto, de um lado, o direito a escolher os governantes quanto, de outro, o direito de candidatar-se aos cargos eletivos, é o primeiro que é mais definitivo, visto que uma restrição que impeça um cidadão de integrar o eleitorado implica uma exclusão mais forte do que uma restrição que o torne inelegível (o direito de votar, nas democracias modernas, é mais fundamental do que o de candidatar-se, de modo que, perdendo o primeiro, perde-se algo mais básico, perde-se uma condição mais fundamental para o exercício da cidadania).

Essa negativa de participação política aos imigrantes limita o conceito de uma soberania popular, de uma cidadania ampla, que visa respeitar, por meio de sua Constituição Federal de 1988, características de um Estado Nacional Cooperativo, criando um déficit democrático e, também, descontextualizando a imagem de um povo-uno, em uma sociedade que objetiva fundamentalmente promover o bem de todos, sem preconceitos de origem, raça, sexo, cor, idade e quaisquer outras formas de discriminação (Art. 3 IV , CF/1988). Demonstra Costa $(2018$, p. 84),

A Constituição coloca a igualdade de tratamento e a vedação à discriminação entre brasileiros e estrangeiros como regra, mas seu texto reserva alguns direitos aos 
nacionais, como o acesso a cargos estratégicos (art. 12, §3으) e confere direitos de cidadania apenas aos brasileiros quando veda ao estrangeiro o alistamento eleitoral no art. $14, \S 2$.

Esse é, também, o entendimento de Mendes e Branco (2014), quando afirmam que os estrangeiros não dispõem de direitos políticos, não podendo votar ou ser eleitos para cargos políticos. Não podem exercer outros direitos de cidadania, como a propositura de ação popular e a subscrição de projetos de lei de iniciativa popular. Destacam, assim, Marin e Bartarello (2010, p. 166):

A ação na esfera pública ou, em outras palavras, a participação na decisão acerca das políticas públicas é condição primeira da existência da sociedade democrática, para que a imagem do povo-Uno se concretize, o que não ocorre na democracia que elide a participação cidadã nas políticas públicas.

Desde o ano de 2007, no Brasil, vem se discutindo o direito à participação popular do imigrante ao voto nas eleições municipais e, também, o direito a se eleger como vereador, desde que domiciliados no país.

Foi por meio do Projeto de Emenda Constitucional (PEC) no 14/2007, arquivada em 23/12/2014, que se iniciou a discussão; veio depois a PEC 88/2012, arquivada em 21/12/2018 e, recentemente, a PEC 09/2019, que se encontra, até a data do presente estudo, tramitando no Senado Federal com o mesmo objetivo, sendo que em 06/06/2019 se deu o último andamento ao Projeto, enviando para a Comissão de Constituição, Justiça e Cidadania - CCJ para que o senador relator Veneziano Vital do Rêgo emita relatório. A Lei no 13.445/2017, online, traz em seu Art. 4ㅇ que:

Ao migrante é garantida no território nacional, em condição de igualdade com os nacionais, a inviolabilidade do direito à vida, à liberdade, à igualdade, à segurança e à propriedade, bem como são assegurados: I - direitos e liberdades civis, sociais, culturais e econômicos (grifo nosso).

Direitos civis são aqueles relacionados às liberdades individuais. O Art. 50, da Constituição Federal de 1988, foi o responsável por garanti-los em seu caput e nos demais 78 incisos. A Lei Maior do país embasou-se na Declaração Universal dos Direitos Humanos e em ambos os Pactos Internacionais (Direito Civis e Políticos e de Direitos Econômicos, Sociais e Culturais), todos ratificados e internalizados pelo Brasil, constituindo um rol, não só de direitos 
e garantias fundamentais a todos os cidadãos brasileiros, mas também aos migrantes que escolhem esse país como destino e são recebidos dentro dos trâmites legais.

Piovesan (2004, p. 26) citando os ensinamentos de Sem (2010), quando trata dos direitos civis, sociais, econômicos e culturais evidencia que:

O pleno exercício dos direitos políticos pode implicar o "empoderamento" das populações mais vulneráveis e o aumento de sua capacidade de pressão, articulação e mobilização políticas. Para Amartya Sem, os direitos políticos (incluindo a liberdade de expressão e discussão) são não apenas fundamentais para demandar respostas políticas às necessidades econômicas, mas também centrais para a própria formulação dessas necessidades econômicas.

Como o presente estudo tem a finalidade de trazer a visão do direito ao desenvolvimento do imigrante na concepção das liberdades instrumentais de Sem (2010, p. 55-6), não se pode deixar de trazer a opinião desse autor, no que tange ao não reconhecimento do direito à participação popular do indivíduo na sociedade em que vive:

\begin{abstract}
Nas visões mais estreitas de desenvolvimento (baseadas, por exemplo, no crescimento do PNB ou da industrialização) é comum indagar se a liberdade de participação e dissensão política é ou não "conducente ao desenvolvimento". A luz da visão fundamental do desenvolvimento como liberdade, essa questão pareceria mal formulada, pois não considera a compreensão crucial de que a participação e a dissenção política são partes constitutivas do próprio desenvolvimento. Mesmo uma pessoa muito rica que seja impedida de expressar livremente ou de participar de debates e decisões públicas está sendo privada de algo que ela tem motivos para valorizar. O processo de desenvolvimento, quando julgado pela ampliação da liberdade humana, precisa incluir a eliminação da privação dessa pessoa. Mesmo se ela não tivesse interesse imediato em exercer a liberdade de expressão ou de participação, ainda assim seria uma privação de suas liberdades se ela não pudesse ter escolha nessas questões. O desenvolvimento como liberdade não pode deixar de levar em conta essas privações. A relevância da privação de liberdades políticas ou direitos civis básicos para uma compreensão adequada do desenvolvimento não tem de ser estabelecida por meio de sua contribuição indireta a outras características do desenvolvimento (como o crescimento do PNB ou a promoção da industrialização). Essas liberdades são parte integrante do enriquecimento do processo de desenvolvimento.
\end{abstract}

No que tange à liberdade de debates e discussões públicas, a Lei da Migração, em seu artigo 3o, inciso XIII, garante "[...] o diálogo social na formulação, na execução e na avaliação de políticas migratórias e promoção da participação cidadã do migrante [...]" (BRASIL, 2017, online), ao mesmo tempo em que resguarda, no inciso XIV, o fortalecimento da integração econômica, política, social e cultural dos povos da América Latina, mediante constituição de espaços de cidadania e de livre circulação de pessoas. 
A Lei da Migração garante o direito de discussões e debates públicos visando à integração política, econômica, social e cultural dos migrantes que aqui chegam, já que a força dessas discussões é um dos correlatos da democracia de grande alcance e esses direitos podem fazer com que a própria democracia funcione melhor.

Desde 2007, está em pauta no Congresso Nacional, a discussão sobre direito de votar e ser votado do imigrante domiciliado no Brasil nas eleições municipais, por meio do Projeto de Emenda Constitucional (PEC 09/2019) em trâmite. Por mais valiosa que a democracia seja e sirva de fonte fundamental para oportunidade social, segundo Sen (2010), existe ainda a necessidade de examinar os caminhos e os meios para funcionar bem e realizar seus potenciais.

Os direitos políticos dos migrantes internacionais constituem um tema central da agenda de direitos humanos (CHELIUS, 2011) e fazem parte da discussão dos países onde há uma democracia pluralista, onde o conceito de soberania e cidadania ultrapassam as fronteiras geográficas e o tipo sanguíneo do indivíduo.

Härbele (2007 e 2009) traz a necessidade de substituir o pensamento jurídico e político de um Estado Constitucional Nacional fechado, para um Estado Constitucional Cooperativo aberto, que não prioriza a soberania nacional, mas a relativiza para conceder verdadeiro sentido à dignidade humana, como um direito público subjetivo fundamental do indivíduo contra o Estado e contra a sociedade, um dever do Estado em proteger, não somente seus nacionais, mas todo aquele que o escolhe como destino e participa de seu desenvolvimento.

No plano regional, o Brasil é o único Estado-Parte do MERCOSUL que não concede o direito ao voto ao migrante, pois Paraguai e Bolívia permitem o voto na esfera municipal; Venezuela e Argentina nas esferas estaduais e municipais; Chile e Uruguai permitem o pleno exercício do voto, em todos os âmbitos, seja no municipal, estadual e federal. As Constituições do Paraguai, da Argentina, do Chile, da Venezuela e do Uruguai concedem o direito de voto aos migrantes em seus artigos 120, 20, 14, 64 e 78, respectivamente.

O direito à participação política do imigrante no Brasil deve ser efetivado tanto no plano jurídico constitucional quanto no direito material e processual, e parece estar caminhando nessa direção, com a Lei de Migração trazendo as liberdades civis, sociais, 
econômicas e culturais como garantia à população migrante, o direito de se associar, os projetos de emenda constitucional para estabelecer o direito de votar e ser votado nas eleições municipais, Leis Municipais que trazem uma política migratória mais participativa como, por exemplo, a Lei Municipal da cidade de São Paulo no 16.478/2016, que visa garantir aos imigrantes daquela cidade uma efetiva participação social, por meio de Conselhos Municipais de Imigrantes, que dentre diversos objetivos, visa fomentar a participação social e desenvolver ações coordenadas com a sociedade civil, são prováveis exemplos de um direcionamento ao respeito à liberdade política dos imigrantes que chegam no Brasil.

\title{
2.1.2 FACILIDADES ECONÔMICAS AO IMIGRANTE NO BRASIL
}

O acesso ao mercado de trabalho por meio da oportunidade de escolha de uma determinada profissão amplia o exercício da liberdade, portanto, o imigrante quando chega ao país de destino, precisa ter a oportunidade de trabalhar e escolher a atividade que atende suas capacidades anteriores, adquiridas em seu país de origem, pois essas condizem com suas aptidões e possibilitam sua melhor participação e integração na sociedade. Segundo Sen (2010, p. 59):

\begin{abstract}
Facilidades econômicas são oportunidades que os indivíduos têm para utilizar recursos econômicos com propósito de consumo, produção e troca. Os intitulamentos econômicos que uma pessoa tem dependerão dos seus recursos disponíveis, bem como das condições de troca, como os preços relativos e o funcionamento dos mercados. À medida que o processo de desenvolvimento econômico aumenta a renda e a riqueza de um país, estas se refletem no correspondente aumento de intitulamentos econômicos da população.
\end{abstract}

Para o economista, o significado de intitulamento originado do verbo latino, intitulare, representa um conjunto de pacotes alternativos de bens que, podem ser adquiridos mediante o uso de vários canais legais disponíveis para uma pessoa, formados pelo pacote original de bens que ela possui e pelos vários pacotes alternativos que ela pode adquirir por meio do comércio e produção, denominados intitulamento de troca (SEM, 2020, grifo do autor).

Nessa parte do presente estudo se analisam os intitulamentos de troca do imigrante no Brasil, no que tangem às facilidades que possuem, em exercer sua profissão de origem por 
meio da revalidação de seu diploma, de poder ter seu próprio negócio como microempresário e de trabalhar de forma digna no mercado de trabalho (grifo nosso).

O trabalho é um dos maiores bens (intitulamentos) que possui o ser humano, pois a organização da vida desse, é, nitidamente, identificada pela sua vida laboral, da qual depende sua família, sua integração social e sua vida pessoal. Determinada profissão ou trabalho contribui para que o indivíduo integre seus objetivos, sonhos e metas, que são dependentes dos rendimentos dessa atividade.

A Lei de Migração (no 13.445/2017) traz em seu Art. 3ํㅡ, sua base principiológica ao direito do migrante no Brasil: "A política migratória brasileira rege-se pelos seguintes princípios e diretrizes: [...] X - inclusão social, laboral e produtiva do migrante por meio de políticas públicas [...]"; e ainda "[...] XXI - promoção do reconhecimento acadêmico e do exercício profissional no Brasil, nos termos da lei" (BRASIL, 2017, online);

O exercício de atividade remunerada é vedado ao imigrante que se encontre no Brasil sob amparo do visto de visita (Art. 13 da Lei no 13.445/2017), podendo apenas receber pagamento de governo, de empregador brasileiro ou de entidade privada, a título de diária, ajuda de custo, cachê, pró-labore ou outras despesas com a viagem, bem como concorrer a prêmios, inclusive em dinheiro, em competições desportivas e em concursos artísticos ou culturais. Nas demais espécies de vistos como, por exemplo, temporário, oficial, cortesia e diplomático, ao residente fronteiriço e aos apátridas, são concedidos o direito de exercerem atividades remuneradas como traduzem os artigos 14 a 18, 23, 24 e 26 respectivamente da supracitada Lei de Migração.

No Brasil, a conjectura do trabalho do imigrante está prevista especificamente na Lei de Migração (no 13.445/2017), na Lei no 9.474/97 (Lei do Refúgio), e na Lei trabalhista (Consolidação das Leis Trabalhistas- Decreto-Lei no 5.452 de 1ㅇ de maio de 1943), Lei essa bastante antiga, que não privilegiava direitos aos imigrantes que adentravam ao país, todavia, com a reforma trabalhista instrumentalizada pela Lei no 13.467 de 13 de julho de 2017, que entrou em vigor em 11 de novembro do mesmo ano e a própria Lei de Migração, que entrou em vigor 21/11/2017, portanto, 10 dias após a Lei da reforma trabalhista, houve um aumento significativo na procura por vistos de trabalho por imigrantes no país, isso porque lhes foi conferido um tratamento igualitário ao dos trabalhadores brasileiros (pela Lei de Migração), 
possibilidade de os empregados imigrantes se filiarem aos sindicados e federação, os mesmos direitos trabalhistas concedidos aos brasileiros natos e naturalizados e, ainda, a desburocratização do acesso do imigrante aos serviços públicos e ao mercado de trabalho por meio da emissão de Carteira de Trabalho e Previdência Social (CTPS).

A Lei no 13.445/2017 e o Decreto no 9.199/2017 passaram a reger a condição do imigrante no país e estabeleceram a competência legal da Coordenação-Geral de Imigração Laboral (CGIL) para emitir autorizações de residências para fins laborais, nos termos das Resoluções Normativas editadas pelo Conselho Nacional de Imigração (CNIg). Nesse contexto, o imigrante para trabalhar no Brasil, com vínculo empregatício ou não, salvo exceções, necessita de autorização de Residência para fins laborais. São várias Resoluções Normativas que mudam ao longo do tempo e se alteram facilmente por meio de outras, que surgem causando insegurança jurídica aos imigrantes que procuram adentrar no mercado de trabalho. De dezembro de 2017 a julho de 2020 foram mais de 42 resoluções normativas tratando somente da autorização de residência no país.

\section{CONSIDERAÇÕES FINAIS}

As autorizações de residência prévia a imigrantes são exigidas pelas autoridades consulares brasileiras, para efeito de concessão de visto temporário aos imigrantes que desejem vir ao Brasil a trabalho. Por sua vez, a categoria de autorização de residência, é utilizada quando a pessoa já se encontra no Brasil, não necessitando mais sair do país para receber outro visto.

O imigrante que aqui se estabelece, tem como amparo de seus direitos uma Constituição Federal Cidadã que o resguarda, uma Lei de Migração capaz de trazer princípios e garantias revolucionários de direito e acolhimento, portarias, resoluções de órgãos da Administração Pública que visam defender o direito a saúde, educação, ao pleno emprego, a benefícios assistenciais e a clareza das informações a todos imigrantes no país, porém, não há proteção efetiva a esses direitos conquistados por meio de políticas públicas que os assegure.

A falta de acolhimento por parte do Estado e da sociedade brasileira por meio de políticas públicas e a falsa ideia de que imigrantes são "estranhos" que batem à porta são os 
empecilhos para o melhor desenvolvimento social e econômico desses braços que escolheram o Brasil como destino transitório ou final de sua jornada.

Durante o transcorrer do século passado aos dias atuais, não deixaram de surgir Leis e estudos filosóficos, sociológicos, antropológicos e jurídicos, visando à proteção desses direitos aos imigrantes, todavia, se a vontade política não assumir o protagonismo dessa luta por meio de políticas públicas que os promova, o desenvolvimento do país deixará de ter um compromisso sério com as possiblidades de liberdade.

\section{REFERÊNCIAS}

AMARAL, Ana Paula Martins; COSTA, Luiz Rosado. A (não) criminalização das migrações e políticas migratórias no Brasil: do Estatuto do Estrangeiro À Nova Lei de Migração. Justiça do Direito, v.31, n.2, 2017.

BAENINGER, Rosana et al. (orgs.). Migrações sul-sul. Campinas: Nepo/Unicamp, 2018. BRASIL. Constituição da República Federativa do Brasil de 1988. Disponível em: <http://www.planalto.gov.br/ccivil_03/Constituicao/Constituicao.htm>. Acesso em: 10 set. 2020.

BRASIL. Decreto no 9.199, de 20 de novembro de 2017. Regulamenta a Lei no 13.445, de 24 de maio de 2017, que institui a Lei de Migração. Disponível em: <http://www.planalto.gov.br/ccivil_03/_ato2015-2018/2017/decreto/d9199.htm>. Acesso em 20 nov. 2020.

BRASIL. ESTADO DE SÃO PAULO. Lei no 16.478 de 8 de julho de 2016. Institui a Política Municipal para a População Imigrante, dispõe sobre seus objetivos, princípios, diretrizes e ações prioritárias, bem como sobre o Conselho Municipal de Imigrantes. $<$ http://legislacao.prefeitura.sp.gov.br/leis/lei-16478-de-08-de-julho-de-2016>. Acesso em 01/10/2020.

BRASIL. Lei no 5.452 de 1o de maio de 1943. Aprova a Consolidação das Leis do Trabalho. Disponível em: <http://www.planalto.gov.br/ccivil_03/decreto-lei/del5452.htm>. Acesso em 10 nov. 2020.

BRASIL. Lei $n$ 0 9.474/97, de 22 de julho de 1997. Define mecanismos para a implementação do Estatuto dos Refugiados de 1951, e determina outras providências. Disponível em: <http://www.planalto.gov.br/ccivil_03/leis/l9474.htm>. Acesso em 10 nov. 2020.

BRASIL. Planalto. Lei $\mathbf{n} \mathbf{0}$ 13.445, de 24 de maio de 2017. Institui a Lei de Migração. Disponível em: <http://www.planalto.gov.br/ccivil_03/_ato2015-2018/2017/lei/l13445.htm>. Acesso em 31 jul. 2020. 
BRASIL. PORTAL DA TRANSPARÊNCIA. Legislação. 2020. Disponível em: <http://www.portaltransparencia.gov.br/sobre/legislacao>. Acesso em: 10 nov. 2020.

CAMPELLO. Lívia Gaigher Bosio; SILVEIRA, Vladmir Oliveira da. Dignidade, Cidadania e Direitos Humanos. In: Anais do XIX Encontro Nacional do CONPEDI em Fortaleza. 2010. Disponível <htttp://www.publicadireito.com.br/conpedi/Manaus/arquivos/anais /fortaleza/3914.pdf>. Acesso em 01 out. 2017.

CHELIUS, Leticia Calderón. O que há por trás do direito ao voto dos emigrantes internacionais? Teoria, história e cidadania demandante. Contexto int., Rio de Janeiro, v. 33, n. 1, p. 231-250, june 2011. Disponível: <http://www.scielo.br/scielo.php?script=sci_ arttext\&pid=S0102$85292011000100010 \&$ Ing=en\&nrm=iso>. Acesso em 05 out. 2020.

COSTA, Luiz Rosado. A construção de uma fase de direitos humanos na política migratória brasileira. 2018. 116 f. Dissertação (programa de pós-graduação em direito) - Universidade Federal de Mato Grosso do Sul.

DUPAS, Elaine. Nova lei de migração: a possibilidade de reconhecimento do imigrante como sujeito de Direitos Humanos no Brasil. 2018. 138 f. Dissertação (programa de pós-graduação em Fronteiras e Direitos Humanos) - Faculdade de Direito e Relações Internacionais, Universidade Federal da Grande Dourados.

HARARI, Yuval Noah. 21 lições para o século 21. Trad. Paulo Geiger. 1ạ ed. São Paulo: Companhia das Letras, 2018.

HÄRBELE, Peter. A dignidade humana como fundamento da comunidade estatal. In: SARLET, Ingo Wolfgang (Org.). Dimensões da Dignidade: Ensaios de Filosofia do Direito e Direito Constitucional. 2a ed. Porto Alegre, RS: Livraria do Advogado, 2009.

HÄRBELE, Peter. Estado Constitucional Cooperativo. Trad. Marcos Augusto Maliska e Elisete ANTONIUK. Rio de Janeiro: Renovar, 2007.

MARIN, Jeferson Dytz; BERTARELLO, Marina. A realização da democracia por meio da participação nas políticas públicas: a afirmação democrática do programa nacional de direito humanos (PNDH-3). Revista Estudos Jurídicos UNESP, Franca, A. 14 n.19, 2010. p. 163-178.

MENDES. Gilmar Ferreira; BRANCO, Paulo Gustavo Bonet. Curso de Direito Constitucional. 9a ed. São Paulo: Saraiva: 2014.

MEZZAROBA, Orides; SILVEIRA, Vladmir Oliveira da. O princípio da dignidade da pessoa humana: uma leitura da efetividade, da cidadania e direitos humanos por meio dos desafios frente à globalização. Revista de Investigações Constitucionais, Curitiba, vol.5, n.1, p.273-293, jan./abr. 2018. 
PIOVESAN, Flavia. Direitos sociais, econômicos e culturais e direitos civis e políticos. Sur, Rev. int. direitos humanos. São Paulo, v. 1, n. 1, p. 20-47, 2004. Disponível em <http://www.scielo.br/scielo.php?script=sci_arttext\&pid=S180664452004000100003\&lng=e $\mathrm{n} \& \mathrm{nrm}=\mathrm{iso}>$. Acesso em 05 de out de 2020.

REIS, Claudio Araújo Constituição de 1988: O Brasil 20 Anos Depois. Os Alicerces da Redemocratização. Todo Poder Emana do Povo: o exercício da soberana popular e a Constituição de 1988. Disponível em <https://www12.senado.leg.br/publicacoes/estudoslegislativos/tipos-deestudos/outras-publicacoes/volume-i-constituicao-de-1988/principios-edireitosfundamentais-todo-o-poder-emana-do-povo-o-exercicio-da-soberania-populare-aconstituicao-de-1988>. Acesso em 03 out.2020.

SALERNO, Marília; BERTACO, Luciana Marques. A Condição Jurídica do Estrangeiro a Trabalho no Brasil. Revista do Direito Privado da UEL, volume 2, número 2. 2007. Disponível: <http://www.uel.br/revistas/direitoprivado/artigos/Marilia_e_Luciana_A__ condi\% C3\%A7\%C3\%A3o_jur\%C3\%ADdica_estrangeiro_trabalho_Brasil.pdf>. Acesso em 11 nov 2020.

SANTOS, Heloisa Souza dos; MEDEIROS, André Aparecido. Migração e Acesso a Serviços de Saúde: A necessidade da Pauta intercultural para o cumprimento dos direitos humanos. Disponível em: <http://www.inscricoes.fmb.unesp.br/upload/trabalhos/20177311134.pdf>. Acesso em 22 out 2020.

SARLET, Ingo Wolfgang (Org). Direitos Fundamentais Sociais, Estudo de Direito Constitucional Internacional e Comparado. Rio de Janeiro e São Paulo: Renovar, 2003.

SEN, Amartya. Desenvolvimento como liberdade. Tradução de Laura Teixeira. São Paulo: Companhia das letras, 2010.

SILVA, César Augusto S. da. A política migratória brasileira para refugiados (1998-2014). Curitiba: Íthala, 2015.

TRINDADE, Antônio Augusto Cançado. A humanização do direito internacional. Belo Horizonte: Del Rey, 2006.

VEDOVATO, Luís Renato; ASSIS, Ana Elisa Spaolonzi Queiroz Assis. Os vetos à nova lei de migração brasileira: a interpretação como um passo necessário. In: BAENINGER, Rosana et al. (orgs.). Migrações sul-sul. Campinas: Nepo/Unicamp, 2018. p. 597-608.

ZAMBAM, Neuro José. A teoria da justiça de Amartya Sen: liberdade e desenvolvimento sustentável. 2009. 189 f. Tese (Doutorado em Filosofia e Ciências Humanas) - Pontifícia Universidade Católica do Rio Grande do Sul, Porto Alegre, 2009. 